\title{
Violência policial e o debate no Twitter em Portugal: o caso do Bairro da Jamaica
}

\author{
Police violence and the debate on Twitter in Portugal: the case of Bairro da Jamaica \\ Violencia policial y el debate en Twitter en Portugal: el caso del Bairro da Jamaica
}

DOI: https://doi.org/10.1590/1809-5844202018

\author{
Beatriz Nascimento Teles ${ }^{1}$ \\ https://orcid.org/0000-0001-8325-6033
}

${ }^{1}$ (Instituto Universitário de Lisboa, Escola de Sociologia e Políticas Públicas, Doutorado em Ciências da Comunicação. Lisboa, Portugal).

\section{Resumo}

O presente artigo apresenta uma análise da comunicação no Twitter a respeito de um caso de violência policial ocorrido no Bairro da Jamaica, distrito de Setúbal, em Portugal. O objetivo é identificar de que forma a violência é naturalizada no discurso público e quais os principais argumentos utilizados. A partir de uma análise qualitativa dos posts sobre o evento, percebe-se que alguns temas estiveram presentes, sendo eles: o uso de violência excessiva por agentes da polícia, o racismo, o lugar dos negros e afrodescendentes na sociedade portuguesa, e a atribuição de responsabilidades a respeito do ocorrido. Em conformidade com estudos anteriores, discussões sobre raça e racismo nas redes sociais tendem a seguir eventos de violência policial. Nesse sentido, o Twitter é usado como meio para a expressão de narrativas a respeito do evento e para a reafirmação de estereótipos como justificativa para a ação da polícia.

Palavras-chave: Bairro da Jamaica. Portugal. Racismo. Violência policial. Twitter.

\begin{abstract}
This paper presents an analysis of the communication on Twitter about a case of police violence that happened in Bairro da Jamaica, district of Setubal, in Portugal. The aim is to identify in which ways the public discourse naturalizes violence and which are the main arguments used. Using qualitative analysis of tweets, it was possible to identify the following main themes in discussion: the excessive use of violence by police agents, racism, the place of black people and African descendant people in the Portuguese society, and the liability about the event. In accordance with other studies, social media conversations about race and racism tend to be related to news events of police violence. The analysis shows that Twitter is used as a medium to express narratives about the news event and also to reaffirm stereotypes to justify police action.
\end{abstract}

Keywords: Bairro da Jamaica. Portugal. Racism. Police violence, Twitter. 


\section{Resumen}

En este artículo se presenta un análisis de la comunicación en Twitter acerca de un caso de violencia policial que ocurrió en el barrio de Jamaica, distrito de Setúbal en Portugal. El objetivo es identificar de qué forma la violencia se naturaliza en el discurso público y cuáles son los principales argumentos utilizados. A partir de un análisis cualitativo de los mensajes sobre el evento, es evidente que algunos temas se discutieron, tales como: el uso de violencia excesiva por parte de los agentes de policía, el racismo, el lugar de los negros y los afrodescendientes en la sociedad portuguesa, y la asignación de responsabilidades con respecto a lo ocurrido. De acuerdo con estudios anteriores, discusiones sobre raza y racismo en las redes sociales tienden a seguir eventos de violencia policial. En ese sentido, Twitter es usado como medio para la expresión de narrativas acerca del evento y para la reafirmación de estereotipos como justificación para la acción de la policía.

Palabras clave: Bairro da Jamaica. Portugal. Racismo. Violencia policial. Twitter.

\section{Introdução}

O fenômeno do racismo e suas formas de expressão são social e historicamente moldados (BONILLA-SILVA, 2006). Nesse sentido, desde o Holocausto o racismo vem sendo expressado de forma muito mais sutil (VALA; BRITO; LOPES, 1999). Ainda assim, em países como Portugal, com uma história de colonialismo e escravidão, o racismo e a ideia de raça têm profundas raízes históricas (CABECINHAS; CUNHA, 2003, HENRIQUES, 2018). As redes sociais representam atualmente uma nova arena de debate sobre raça e racismo (ANDERSON; HITLIN, 2016). Ao mesmo tempo, os dados públicos permitem a investigação sobre mudanças de comportamento e de percepção sobre problemas sociais (CARDOSO; JACOBETTY, 2013).

O objetivo deste artigo é identificar de que forma a violência policial contra os negros é interpretada pelos usuários do Twitter, num caso específico de violência ocorrido no Bairro da Jamaica, distrito de Setúbal, em Portugal, em janeiro de 2019. Além disso, pretende-se identificar se há uma naturalização da violência contra negros, quais os enquadramentos usados nas argumentações e, no âmbito geral, identificar indícios sobre qual é a função do Twitter nas discussões sobre o racismo em Portugal.

Para isso, será realizada uma contextualização histórica, o que permite conectar a problemática do racismo atual e suas raízes coloniais em Portugal. Em seguida, será feita uma breve narrativa sobre o caso do Bairro da Jamaica. Sendo esta uma análise do racismo nas redes sociais, serão realizadas algumas considerações sobre o estado da arte, apontando para similaridades e diferenças no que concerne às conclusões deste estudo. Foi adotada uma abordagem qualitativa para a análise dos posts no Twitter, tendo sido coletados 2.067 posts num período de dez dias, entre os dias 20 e 30 de janeiro de 2019. Deste conjunto de dados, foram analisados e codificados 564 posts de acordo com categorias temáticas previamente elaboradas. 


\section{As raízes do racismo português}

Na realidade colonial, a ocupação por parte do colonizador pressupunha a sujeição do colonizado a um lugar inferior, “entre o status de sujeito e objeto” (MBEMBE, 2016, p. 135). Ao escravo era decretada a "morte social” e retirado qualquer traço de humanidade (MBEMBE, 2016, p. 131). A realidade atual é diferente, mas não eliminou a diferenciação e a hierarquização social. A ideia de raça estrutura a percepção sobre os outros (CABECINHAS; AMÂNCIO, 2004) e ainda é uma das bases para a hierarquização da sociedade (CABECINHAS; AMÂNCIO, 2003). A construção social das minorias resulta da ideia de que, dentro ou fora de um Estado soberano, alguns tem mais direitos do que outros (APPADURAI, 2009) e que, no limite, alguns merecem mais viver do que outros (MBEMBE, 2016). Nesse sentido, para Achille Mbembe, a ideia de raça sempre esteve presente na história do Ocidente como forma de desumanizar e dominar outros povos, com a função de "regular a distribuição da morte" (MBEMBE, 2016). Portanto, o racismo e suas diversas formas de manifestação estão, em Portugal, intimamente ligadas com a história colonial deste país. A situação de desigualdade e, por vezes, invisibilidade que se encontra a população negra em Portugal tem raízes nos últimos séculos da história portuguesa (HENRIQUES, 2018).

Portugal foi uma potência colonial até relativamente pouco tempo. O período colonial português somente se encerrou com a Revolução dos Cravos e consequente fim do regime salazarista, em 1974. A partir daí as guerras coloniais pela independência, algumas delas iniciadas há mais de dez anos, como é o caso de Angola, foram sucedidas pela independência de fato.

Após a independência do Brasil, em 1822, se iniciou um processo de reestruturação das colônias portuguesas, agora com foco na África (ALEXANDRE, 2000). Apesar da independência do Brasil, Portugal continuaria a intermediar o tráfico de escravos para suprir a demanda de mão de obra neste novo país. Embora se comece já no início do século XIX um movimento de abolição do trabalho escravo, movimento este liderado pela Inglaterra, o tráfico de escravos no Atlântico continuou a ser uma importante atividade econômica para os negociantes portugueses. Além de ser uma atividade lucrativa por si só, o trabalho escravo era a base das economias de plantação nas colônias portuguesas, como era o caso das plantações de cacau em São Tomé, que continuaram a usar mão de obra escrava ou serviçal até o século XX (DIAS, 2000). Em Moçambique, o tráfico de escravos foi a principal atividade comercial no início do século XIX, além de ser a base das principais atividades econômicas da colônia, como o comércio de marfim e de ouro (CAPELA, 2000).

O trabalho escravo foi a base de todo um sistema mercantilista protecionista, autoritário e anticapitalista, baseado na exploração dos recursos naturais das colônias africanas até o século XX (TORRES, 2000). A especificidade do caso português é devido, portanto, não à natureza do sistema mercantilista e escravagista, mas ao prolongamento desta realidade, 
o que permitiu até muito tarde a utilização de trabalho forçado (NETO, 2000) e negou a cidadania a grande parte dos africanos das suas colônias até 1961 (ALEXANDRE, 1999).

Além de ser base do sistema colonial português, a utilização do trabalho escravo permaneceu até tão tarde também por conta da ausência de uma mentalidade abolicionista em Portugal e pela predominância da ambivalência com relação a este assunto, o que não contribuía nem para a regulação nem para a fiscalização do tráfico (MARQUES, 2000). Tanto a colonização quanto a relação de Portugal com os africanos eram pautadas pela ideia de uma missão civilizadora na África e, portanto, pela ideia de superioridade biológica e cultural dos portugueses com relação aos africanos (CASTELO, 2011).

Ainda que após a Segunda Guerra a pressão externa pela descolonização da África tenha provocado mudanças na legislação e no discurso por parte de Portugal, a colonização ainda era um importante componente da identidade nacional. Uma das respostas ao contexto internacional anticolonialista e às guerras de independência das colônias africanas foi uma mudança do discurso, por parte do Estado Novo, que adaptou o discurso luso-tropicalista de Gilberto Freire ao contexto do moderno império africano (CASTELO, 2011). Entretanto, a ideia de uma excepcional capacidade dos portugueses de lidar com o outro africano não acabou com o fim do Estado Novo, já que continuou a ser reproduzida pelas elites políticas portuguesas após a ditadura, como parte de sua identidade nacional (ALEXANDRE, 1999).

Esta característica da construção e afirmação da identidade nacional portuguesa representa um desafio ainda hoje ao se falar em racismo em Portugal. Após a revolução de 1974, uma primeira fase de imigração para Portugal foi marcada pela vinda de pessoas, principalmente das ex-colônias como Cabo Verde, Angola e Guiné-Bissau (DIAS, 2012, OLIVEIRA, 2012), em grande parte devido à crescente demanda de mão-de-obra para a construção civil. Parte dessas populações não tinha condições financeiras de viver no centro da cidade e fizeram crescer os bairros da periferia de Lisboa, muitos deles no município de Amadora (RAPOSO; VARELA, 2016).

A questão da habitação e da precariedade dos bairros da periferia de Lisboa é apenas um dos vários problemas estruturais com os quais a população negra e afrodescendente deve lidar em Portugal (ECRI, 2018). O acesso ao direito a uma habitação digna é ainda mais prejudicado se pensarmos na dificuldade encontrada muitas vezes pela população afrodescendente em conseguir a nacionalidade portuguesa, mesmo tendo nascido em Portugal (HENRIQUES, 2018). O racismo estrutural, portanto, se estende ainda por uma série de outras áreas básicas na vida dos negros, como a justiça e a educação. Alguns estudos tem demonstrado de que forma, em Portugal, a ausência de representação dos negros nos materiais didáticos e a forma como a história da colonização é retratada dificulta tanto a autoafirmação dessa população quanto a própria discussão pública de questões raciais (ECRI, 2018, ARAÚJO; MAESO, 2013). Nesse sentido, o questionamento subjacente em todos estes estudos diz respeito à possibilidade ou não de os negros ascenderem socialmente em Portugal ainda hoje dadas as barreiras com raízes históricas que se impõem. 
Apesar do isolamento em que muitas vezes vivem os negros em Portugal, que representam uma parte considerável dos habitantes das periferias de Lisboa (RAPOSO; VARELA, 2016), eventualmente episódios fazem lembrar ao restante da sociedade portuguesa de que talvez, afinal, este não seja um país onde a cor não importa. Nesse contexto, a responsabilidade do Estado no fracasso em lidar com problemas estruturais e em reconhecer a cidadania plena de toda a sua população é convertida em culpabilização da própria população negra pela sua realidade.

Atos de violência policial representam a atuação dos aparelhos repressivos de Estado na luta pela manutenção da hierarquia e da coesão social (ALTHUSSER, 1983), sob uma lógica racista das relações sociais (BONILLA-SILVA, 2006). Portanto, "não existe prática senão através de e sob uma ideologia” e "não existe ideologia senão através do sujeito e para sujeitos” (ALTHUSSER, 1983, p. 42). Em Portugal, alguns destes episódios aconteceram nos últimos anos, como foi um caso na Cova da Moura, em 2015, e no Bairro da Jamaica, em janeiro de 2019. Estes casos foram seguidos de uma repercussão marcada também pela violência simbólica (BOURDIEU, 2000), através da naturalização, banalização e, algumas vezes, defesa da violência como forma legítima de resolução de conflitos.

\section{Caso do Bairro da Jamaica}

No dia 20 de janeiro de 2019, a Polícia de Segurança Pública (PSP) foi chamada ao Bairro da Jamaica, no distrito de Setúbal, para intervir em um conflito entre moradores. Ao chegar lá, PSP e alguns moradores entraram em conflito, situação que foi registrada em vídeo aparentemente por moradores do bairro. No vídeo, chama a atenção a violência desproporcional que é empregada pelos policiais para lidar com os moradores, alguns deles idosos. Talvez pelo fato de o acontecimento ter sido registrado e divulgado nas redes sociais através de vídeo, o que se percebe a partir do dia 20 de janeiro é uma ampla discussão sobre o caso, tanto nos meios de comunicação tradicionais quanto nas redes sociais.

Nesse sentido, o primeiro objetivo da análise que será exposta a seguir é justamente identificar, através da comunicação realizada no Twitter, a forma como a violência policial é interpretada neste contexto comunicativo, com foco em um caso específico, o caso do Bairro da Jamaica.

\section{O racismo nas redes sociais}

Em estudos anteriores, percebe-se que discussões sobre raça e racismo nas redes sociais tendem a seguir eventos de violência policial, sendo que estes eventos servem como catalizadores para o debate nas redes sociais (ANDERSON; HITLIN, 2016). Ainda que os meios de comunicação tradicionais, como a TV e os jornais, continuem a ser a principal referência informativa para discutir questões raciais e racismo (BEN-DAVID; 
MATAMOROS-FERNÁNDEZ, 2016, HUGHEY; DANIELS, 2013, STEINFELDT et al, 2010), as redes sociais são um espaço de expressão de opiniões sobre aquilo que é reportado pela mídia ou por atores políticos (ANDERSON; HITLIN, 2016). Nesse sentido, as redes sociais podem ser vistas como um recurso para interagir com a realidade, construir pertenças e defender interesses (CARDOSO; JACOBETTY, 2013).

Mesmo que não se possa afirmar que as redes sociais constroem nichos, o que se sabe é que neste contexto comunicativo os nichos são visíveis, o que nos dá indícios da fragmentação na sociedade (SUNSTEIN, 2017). Se, por um lado, a capacidade da sociedade civil de se unir em torno da luta por direitos civis e igualdade é muito maior no contexto da sociedade em rede (CASTELLS, 2003; JOSEPH, 2012), é também verdade que grupos que questionam e deslegitimam essa luta utilizam as redes sociais como ferramentas de comunicação (FAULKNER; BLIUC, 2016, RECUERO, 2015).

Com relação à expressão pública de discursos racistas, nota-se uma tendência de transformação nas últimas décadas. O discurso racista flagrante com base na crença da existência de uma hierarquia biológica entre raças, deu lugar a um discurso muito mais sutil, mas ainda assim baseado numa hierarquia social (BONILLA-SILVA, 2006, BONILLA-SILVA; LEWIS; EMBRICK, 2004, MEERTENS; PETTIGREW, 1999, VALA; ALEXANDRE, 1999). Isso não significa, porém, que o racismo não continue a ser danoso para suas vítimas, pelo contrário. O uso de estereótipos é comum para justificar e naturalizar comportamentos sociais de grupos étnicos e colocá-los como culpados de sua própria realidade social (BONILLA-SILVA, 2006, HENRIQUES, 2018, TAGUIEFF, 1990). A “ambivalência do pensamento liberal” (APPADURAI, 2009) permite que a ideia da meritocracia seja utilizada no contexto discursivo de hierarquização cultural para negar o racismo e justificar as desigualdades sociais (BONILLA-SILVA, 2006; TAGUIEFF, 1990). O que se percebe é a representação direta de algumas minorias como imigrantes, criminosos e, portanto, uma ameaça à segurança da sociedade na qual estão inseridos (BEN-DAVID; MATAMOROS-FERNÁNDEZ, 2016, FAULKNER; BLIUC, 2016), o que deslegitima a luta contra a discriminação racial e naturaliza as desigualdades sociais.

É nesse contexto que se propõe uma análise do discurso realizado no Twitter a respeito do caso de violência policial ocorrido em janeiro de 2019 no Bairro da Jamaica, em Setúbal, Portugal. Pouco se sabe sobre o impacto que a reprodução nas redes sociais do discurso racista tem sobre a opinião pública e sobre a realidade material dos negros. Nem sabemos ao certo qual a influência que o discurso tem sobre a prática. Porém, parte-se da premissa de que o discurso racista tem papel fundamental na construção e reprodução de estereótipos, que são um importante componente da "manutenção das desigualdades sociais” (DIJK, 2012, p. 32). O objetivo deste estudo, portanto, é apresentar os resultados de uma análise de dados do Twitter, através da análise qualitativa dos posts relacionados com o caso do Bairro da Jamaica. Além de identificar se há uma naturalização do uso da violência, pretende-se identificar quais os principais enquadramentos utilizados para justificar a ação 
da polícia. Pretende-se também buscar indícios sobre qual a função do Twitter no contexto das discussões sobre racismo e relações raciais em Portugal.

\section{Metodologia}

Foi realizada uma análise qualitativa dos dados do Twitter, nomeadamente de posts públicos publicados nesta plataforma, a partir de uma análise crítica do discurso (BRAUN; CLARKE, 2006, DIJK, 2012). Para isso, foi realizada a codificação dos posts em categorias temáticas previamente elaboradas.

\section{Coleta de dados}

O período de coleta de dados foi de 10 dias, entre o dia 20 e 30 de janeiro de 2019. Este período de coleta se justifica pelo fato de que, dessa forma, foi possível verificar todo o desenvolvimento das discussões sobre o caso do Bairro da Jamaica, que ocorreu na manhã do dia 20. Foram coletados um total de 2.067 posts, entre tuítes, retuítes e compartilhamentos. Deste total, foram analisados 564 posts, que representam, afinal, o total de posts originais registrados no Twitter neste período após a limpeza dos dados, ou seja, eliminação de posts incompreensíveis ou que estivessem fora do contexto de interesse desta pesquisa (BATRINCA; TRELEAVEN, 2014).

O nosso conjunto de dados, portanto, compõe-se de tuítes, ou seja, posts publicados no Twitter, que se definem como pequenos textos de, no máximo, 280 caracteres. Os posts podem vir acompanhados de um link externo, que muitas vezes consiste em uma notícia de jornal online, num texto de blog, vídeos ou fotos.

Para a coleta dos dados foi utilizada a plataforma Crimson Hexagon, de coleta e análise de dados de redes sociais. Através da delimitação do período de coleta de dados, das palavras-chave, do tipo de posts, do idioma e da localização geográfica do usuário, o Crimson Hexagon é capaz de coletar exclusivamente os dados que se encaixam nos filtros elaborados pelo pesquisador de dentro de todo o universo de dados públicos do Twitter, seja em tempo real ou do histórico (HITLIN, 2015).

\section{Análise de dados}

A análise do conteúdo textual dos posts foi realizada através do programa NVivo. Inicialmente, foram inseridas no programa as categorias de análise para, a seguir, importar os dados a serem analisados e, por fim, proceder à codificação (AHMED et al, 2018). Como o foco desta pesquisa era perceber o enquadramento utilizado pelos usuários do Twitter e não aquele feito pelos meios de comunicação, os tuítes produzidos por estes não foram codificados. 
As categorias de análise previamente elaboradas representam os principais enquadramentos usados para explicar eventos de discriminação racial, nesse caso, a violência policial contra negros e afrodescendentes. Todas estas categorias representam uma concepção, flagrante ou sutil, de uma visão de mundo baseada na hierarquia racial, ou numa concepção estereotipada e pejorativa a respeito dos negros. As categorias elaboradas e sua devida descrição se encontram resumidas na Tabela 1 e em maior detalhe a seguir.

Tabela 1 - Categorias de análise e respectivas definições

\begin{tabular}{|c|c|}
\hline Categoria de análise & Definição \\
\hline Minimização do racismo & $\begin{array}{ll}\cdot & \text { Questão de interpretação (VITIMIZAÇÃO) } \\
\text { - } & \text { Negação da discriminação (BONILLA-SILVA, } \\
\text { 2006, TAGUIEFF, 1990) }\end{array}$ \\
\hline Negros/afrodescendentes x Violência & $\begin{array}{ll}\text { - } & \text { Moradores da periferia: arquétipos de } \\
\text { criminosos (RAPOSO; VARELA, 2016, VALA; } \\
\text { ALEXANDRE, 1999); } \\
\text { - } \quad \text { Relação raça/violência (HENRIQUES, 2018); } \\
\text { - } \quad \text { Blaming the victims (BONILLA-SILVA, 2006); } \\
\text { Estereótipos }\end{array}$ \\
\hline Meritocracia & $\begin{array}{l}\text { - Status social: razões de mérito/esforço individual } \\
\text { (BONILLA-SILVA, 2006) }\end{array}$ \\
\hline Racismo reverso & $\begin{array}{ll}\text { - } & \text { Tratamento diferencial x igualdade de } \\
\text { oportunidades (BONILLA-SILVA, 2006); } & \text { Discriminação racial contra brancos }\end{array}$ \\
\hline
\end{tabular}

Fonte: elaborado pela autora.

\section{Minimização e negação do racismo}

Na prática, a maior parte dos posts que foram codificados nas categorias de análise resumidas na Tabela 1 expressam argumentos em defesa da ação da polícia no Bairro da Jamaica. No caso da minimização e negação do racismo é um pouco diferente, devido ao fato de que, mesmo ao reconhecer que a ação da PSP possa ter sido desproporcional e abusiva, isso não seria necessariamente indício de racismo.

Manos tão a fazer manifs contra o racismo só... tp que o problema não foi o abuso de poder das autoridades... Até pode ter racismo envolvido mas oq aconteceu na Jamaica foi abuso de poder! Devem pensar que polícia só abusa de pretos, brancos sofrem do mesmo. 
Se ocorrer uma situação de violência, mesmo que gratuita, entre polícias melanodérmicos e populares leucodérmicos, será o tema tratado como \#racismo? \#BairroJamaica \#Jamaica.

No primeiro caso, sugere-se que a polícia é sempre violenta e sempre emprega meios abusivos para lidar com conflitos. Não se considera, portanto, que o abuso de poder seja praticado especialmente em bairros da periferia e contra pessoas negras. As categorias de análise não são exclusivas, portanto, o segundo post citado se encaixa também na categoria de racismo reverso, no sentido em que, além de usar ironia para falar de classificações raciais, também parece sugerir que a sociedade civil não se preocupa com o racismo que eventualmente possa ser direcionado a brancos.

Uma outra forma de minimizar e negar o racismo é associar as denúncias a uma estratégia de vitimização ou a uma dramatização desnecessária do assunto.

Gente não dramatizem o que se passou no bairro da Jamaica. A polícia é para manter a ordem social. Obvio que se vocês vão bater nos bófias eles não vos vão dar festinhas. Vocês estão é habituados a ter demasiada liberdade e quando algo não corre a vosso favor já é racismo ou +.

Nesse sentido, além de desconsiderar a possibilidade de que a polícia possa ter agido de forma questionável, também se considera que, de alguma forma, os moradores envolvidos no conflito foram responsáveis pela violência e que isso, afinal, explica a ação da PSP.

\section{Relação negros e criminalidade}

Uma constante no que se refere aos resultados de pesquisas sobre a retórica do racismo atualmente diz respeito à relação direta que se faz entre negros e criminalidade (BONILLASILVA, 2006, HENRIQUES, 2018, TAGUIEFF, 1990, VALA; LOPES; BRITO, 1999). Este tipo de estereótipo se estende aos imigrantes pobres, aos ciganos e aos muçulmanos (AWAN, 2014, CABECINHAS; AMÂNCIO, 2004, MALESIC, 2017).

Essa representação tem como base a ideia de que existe uma relação entre prática de crimes, consumo de drogas, insubordinação e raça. No caso do Bairro da Jamaica, os moradores da periferia, especialmente os negros, foram vistos como arquétipos de criminosos e, portanto, receberam a culpa por serem, a partir deste ponto de vista, naturalmente violentos.

Se vocês soubessem o que se passa todos os dias na Jamaica não estavam aí a mandar bocas. Todos os dias tem de haver intervenção da polícia, todos os dias há tiros, pancada e roubos. E vocês aí a dizer que a polícia é racista. 
A PSP agrediu moradores do bairro da Jamaica. Deve ter sido a primeira vez lá no bairro que o que bateu mais não foi a erva.

Esta agora os pretos da jamaica fazem merda e atiram pedras á PSP e a policia tem de ter moderação...vão tomar no cú vão.

Além da reafirmação de estereótipos sobre os negros, o Bairro da Jamaica é visto como um bairro problemático por definição. Isso é reiteradamente afirmado nos posts. Este suposto fato justifica a ação da polícia e deslegitima qualquer acusação de racismo. O uso de estereótipos e a culpabilização das vítimas é o desenvolvimento normal neste tipo de argumento.

Desculpem lá..PQP, marginais do caralho, coitadinhos deles, espancados pelos arrogantes dos polícias ... Conhecem o bairro? Vão lá dar uma volta a pé e depois digam alguma coisa... Jamaica?? Está tudo dito, só em rendimentos mínimos..

Neste caso, são usados diversos argumentos e se encaixa em, pelo menos, três categorias de análise. Há uma acusação de que os moradores do Bairro da Jamaica são criminosos, mas que se vitimizam e que, além disso, são dependentes de dinheiro público (Rendimento Social de Inserção). Todos estes argumentos usados de forma conjunta têm como objetivo desumanizar as vítimas das agressões e deslegitimar qualquer tentativa de denúncia de racismo.

\section{Meritocracia e liberalismo abstrato}

Outro tipo de argumento utilizado no discurso racista diz respeito à explicação das diferenças de status social e econômico na sociedade (BONILLA-SILVA, 2006, TAGUIEFF, 1990). Diferenças de renda, nos locais de habitação e escolaridade são explicadas mediante argumentos liberais abstratos, como se o status de um indivíduo na sociedade se devesse única e exclusivamente a razões de mérito e de esforço individual (ou falta dele). Este tipo de argumento tem como base a ideia de que características como gosto pelo trabalho, sucesso e poder aquisitivo são resultado também de características étnicas. Faz-se, então, uma associação entre negros e preguiça ou desleixo, estereótipo que tem profundas raízes na história colonial portuguesa (CABECINHAS; CUNHA, 2003).

As gentes do bairro da Jamaica procederam à realização de uma manifestação contra as ações (por sinal completamente válidas) da polícia de segurança publica, com acusações de racismo e injustiça no dever por parte dos políciais. Pergunto-me: Estes seres de etnia negra trabalham? 
A ideia da meritocracia e do gosto pelo trabalho, neste caso, vem acompanhada da expressão da escolha de um lado, ou seja, o lado da polícia, que se fez questão de expressar ao demonstrar apoio às ações que foram praticadas. Além disso, o racismo mais uma vez é expressamente negado.

\section{Racismo reverso}

Por fim, notou-se na repercussão das ações da PSP no Twitter uma tentativa de reverter as acusações de racismo. Os argumentos de racismo reverso se baseiam na crença de que alguns grupos minoritários recebem privilégios do Estado, em forma de ações afirmativas, e que isto fere o princípio da igualdade de oportunidades (BONILLA-SILVA, 2006). Baseia-se também na crença da existência expressiva de discriminação racial contra brancos, sendo que, muitas vezes, com base nestas construções discursivas, esta discriminação seria notada na atitude de negros contra policiais brancos.

Falam de racismo mas esquecem-se que quem praticou racismo nesta situação do bairro da jamaica foram os da raça negra que começaram a atirar pedras ao polícias, daí o desacato. Ou racismo é só a raça caucasiana perante a raça negra?

Racismo xenofobia.!? É bem mais fácil um negro ou mestiço do bairro da Jamaica, no Seixal, ou de qualquer outro bairro ver um estado ocidental proteger os seus direitos legais do que um indivíduo branco numa qualquer sociedade da África. E ainda se queixam.

Vê-se a acusação de que os moradores do Bairro da Jamaica deram início ao problema, supostamente motivados por racismo e não o contrário. O segundo post não só se limita a afirmar que o racismo não exista nos países ocidentais, supostamente civilizados, como também expressa a ideia de que são os brancos que sofrem discriminação racial ao viverem na África. Para além disso, há a ideia de que um cidadão negro ou imigrante não tem o direito de reclamar da sua condição em Portugal.

Para além das categorias que foram previamente definidas, outras duas categorias surgiram a partir da análise dos dados, que foram: defesa da violência e repressão; e relação negros x estrangeiros. Na primeira categoria, foram codificados aqueles posts em que ocorre a defesa explícita ou até mesmo a incitação da violência física da polícia na resolução do conflito no Bairro da Jamaica. A segunda, refere-se aos discursos que insinuam ou afirmam uma representação do negro como estrangeiro e não como português, e isto serve, no âmbito do discurso, para mais uma vez justificar a ação da polícia ou minimizar os seus danos. 


\section{Resultados e discussão}

Assim que o vídeo do conflito no Bairro da Jamaica e as primeiras notícias saíram nos meios de comunicação, deu-se início a uma grande discussão no Twitter. Se os primeiros posts foram de espanto com a força utilizada pelos policiais para resolver a situação, não demorou muito para que diferentes narrativas fossem expostas. A primeira questão que foi debatida no primeiro dia de repercussão do caso diz respeito à explicação a respeito da atuação da polícia. As opiniões se dividiram. Alguns defendiam os moradores do Jamaica que foram agredidos pela polícia, demonstrando indignação no que pareceu um excesso de força usado pela polícia. Outros posts eram mais ambíguos, lamentando os excessos cometidos pela polícia, mas acusando os moradores do Bairro da Jamaica de terem jogado a primeira pedra. Por fim, aproximadamente $1 / 4$ dos posts defendiam a ação da polícia naquele caso, justificando o excesso ou mesmo negando qualquer excesso, devido ao comportamento violento dos moradores do Jamaica.

O Twitter é considerado um local de reflexão e reação sobre acontecimentos da vida cotidiana (ANDERSON; HITLIN, 2016). Porém, não seria um espaço de expressão de novas ideias (YAQUB et al, 2017). Estas afirmações podem ser parcialmente confirmadas neste estudo, já que o número de retuítes é muito superior ao de posts originais: cerca de apenas $27 \%$ dos posts que citavam especificamente o Bairro da Jamaica são posts originais. Por outro lado, considera-se que o Twitter, ao menos neste caso específico, foi usado como ferramenta pelos seus utilizadores para expressar uma versão do que aconteceu, versão esta que pareceu ser formada por um conjunto de diferentes fontes de informação. O que se percebe é a tentativa de algumas pessoas de tentarem criar, nos seus posts, narrativas alternativas às narrativas da mídia. Nesse sentido, é utilizada uma série de estratégias discursivas para que estas diversas narrativas façam sentido. Uma estratégia muito comum é a afirmação de que se obteve informações privilegiadas, de moradores do Bairro da Jamaica ou de policiais, ou seja, de pessoas diretamente envolvidas no caso. Além disso, ao serem citadas uma ou mais notícias da mídia, os usuários do Twitter escrevem a sua própria conclusão da história. A complexidade da questão pareceu estimular as pessoas a determinarem a versão oficial e definitiva do que aconteceu. 
Figura 1 - Volume de posts originais entre 18 e 30 de janeiro

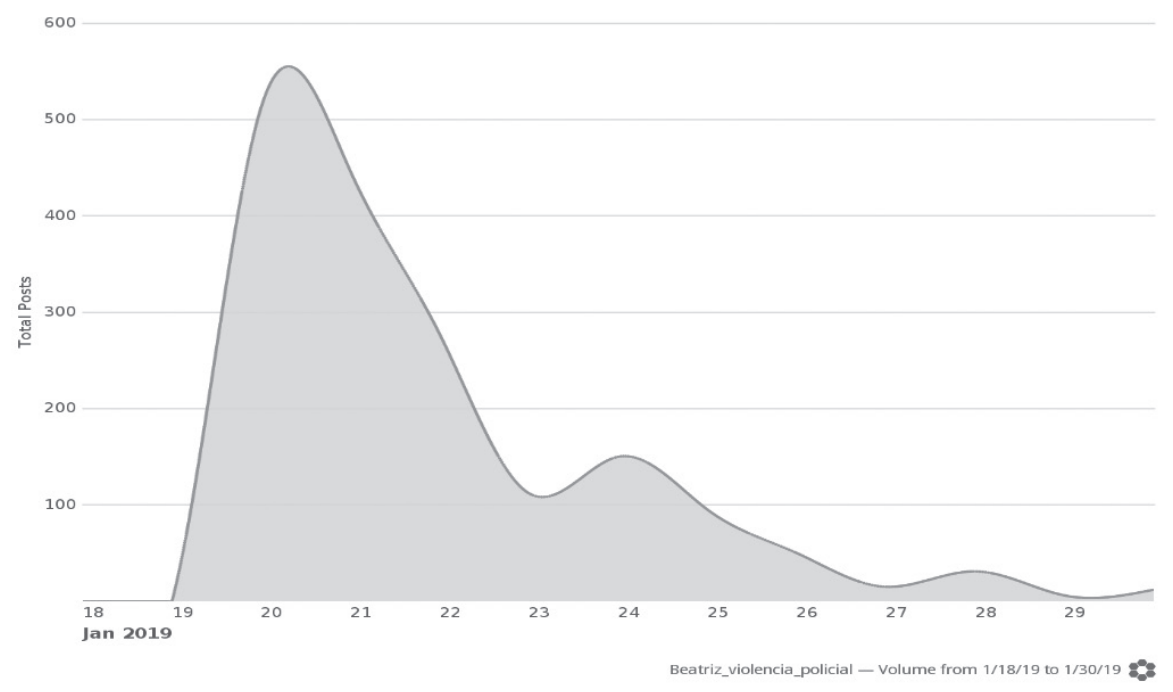

Fonte: Crimson Hexagon (2019).

Nota: Gráfico refere-se a posts que façam menção ao Bairro da Jamaica.

Nestas construções narrativas, com o intuito de defender a ação da polícia, de justificála ou naturalizá-la, destacam-se argumentos que se baseiam em estereótipos a respeito dos negros (BONILLA-SILVA, 2006, HENRIQUES, 2018, RAPOSO; VARELA, 2016, TAGUIEFF, 1990, VALA; ALEXANDRE, 1999). Este definitivamente é o tipo de estratégia discursiva mais utilizada nos dados analisados. Nesse sentido, o negro e morador da periferia é arquétipo de criminoso. Assim, enquanto criminosos, justificam a ação violenta da polícia e são, de forma direta ou indireta, culpados pela violência que sofreram. Em seguida, a minimização ou negação do racismo (Bonilla-Silva, 2006, Henriques, 2018, Taguieff, 1990) é a ideia mais presente. Muitas vezes, porém, o uso de estereótipos e a negação do racismo são complementares, já que a principal ideia que subjaz à negação de que tenha havido racismo é justamente a ideia de que os atos da polícia são justificáveis perante as atitudes criminosas dos moradores do Bairro da Jamaica.

O racismo reverso (BONILLA-SILVA; LEWIS; EMBRICK, 2004) é um argumento também utilizado, mas de forma muito esporádica, para relativizar a possível relação entre violência policial e racismo institucional. Assim, nesses casos, levanta-se a questão de que o racismo não é exclusivamente direcionado aos negros, mas também aos brancos. 
Figura 2 - Distribuição por categoria

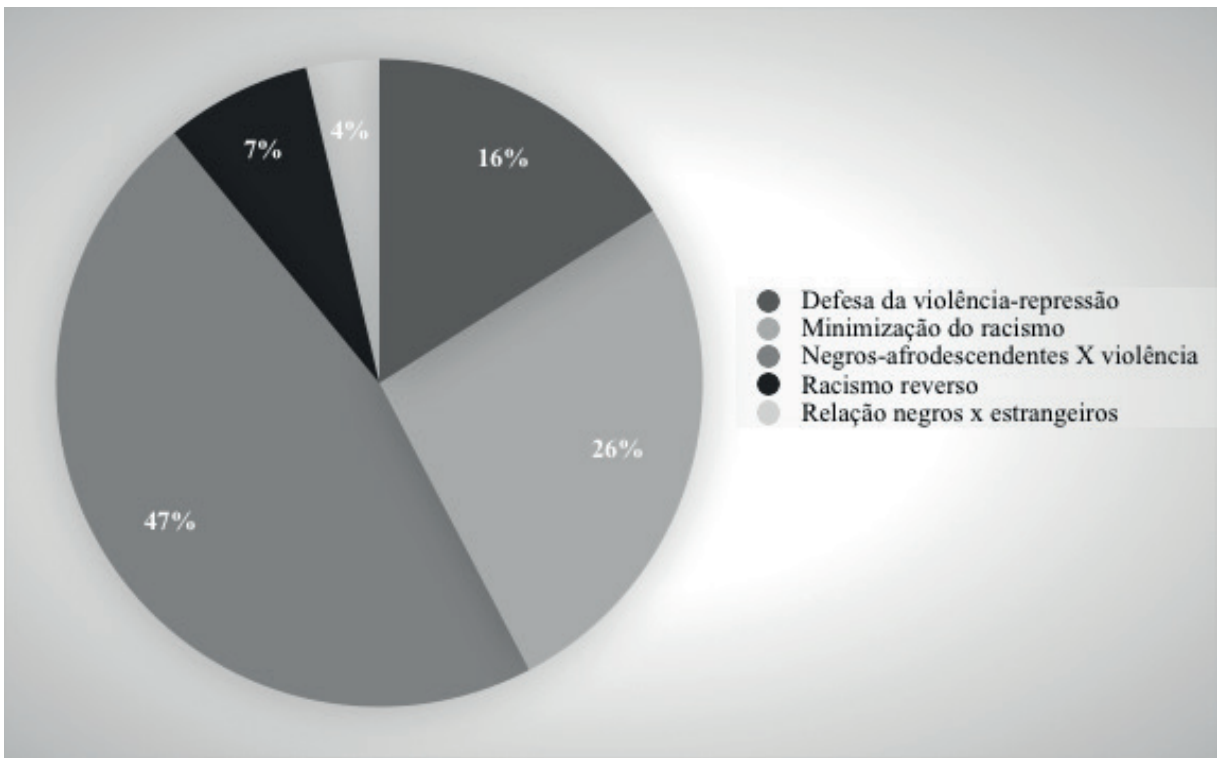

Fonte: elaborado pela autora.

Apesar de ter sido apontado em alguns estudos como um dos principais enquadramentos do racismo moderno, o uso de argumentos liberais e a ideia da meritocracia (Bonilla-Silva, 2006, Taguieff, 1990) também foram pouco utilizadas neste caso específico. Isso não quer dizer que tais ideias não estejam presentes na opinião pública portuguesa, porém, não teve grande expressão nos dados analisados. Uma possível explicação para isso pode advir do fato de que aqueles que defenderam a ação da polícia não se mostraram minimamente interessados em perceber as razões pela qual, por exemplo, existam bairros tão precários e isolados em Portugal, e de quem é a responsabilidade. As discussões, portanto, se limitaram à questão da violência e não da pobreza e da desigualdade.

\section{Conclusão}

O objetivo deste estudo foi demonstrar de que forma a violência policial e o racismo institucional são naturalizados no Twitter em Portugal, com relação a um caso específico de violência ocorrido no Bairro da Jamaica em janeiro de 2019. Muitos dos tuítes analisados reforçam estereótipos a respeito do bairro e seus moradores, ou negam a existência de racismo. A realidade de gueto e de isolamento é então reforçada, mas muitas vezes sem nenhum questionamento sobre as razões por trás desta realidade. Aquela situação é vista como algo já natural e impossível de mudar. Mesmo que não seja possível saber ao certo a influência que a dimensão discursiva e ideológica do racismo tem sobre a realidade material, 
parte-se do pressuposto de que estas dimensões precedem situações de abuso de poder e violência racista e são a base da discriminação racial e das desigualdades sociais.

Como não poderia ser diferente, este estudo tem várias limitações. O Twitter tem uso reduzido em Portugal, além de ser utilizado por uma parcela mais jovem e bem qualificada da sociedade. Portanto, não é possível generalizar os resultados encontrados para toda a sociedade portuguesa. Para além disso, a coleta de dados do Twitter é sempre realizada através do uso de filtros e palavras-chave, o que pode não trazer todos os resultados que sejam úteis para a análise em questão.

O tema deste artigo faz parte de um projeto de tese de Doutorado que tem como foco a naturalização da violência contra negros e afrodescendentes em Portugal, no contexto da comunicação nas redes sociais. Em estudos futuros, pretende-se complementar a análise qualitativa com uma análise quantitativa e uma análise de redes, onde seja possível identificar quais as ligações entre os principais atores envolvidos nas discussões sobre racismo e as possíveis ligações entre estes atores e partidos ou grupos políticos portugueses. Além disso, outra possibilidade interessante é realizar uma análise comparativa entre o discurso pró e contra a ação da polícia nos casos de violência policial.

\section{Referências}

ECRI, European Comission Against Racism and Intolerance. Relatório da ECRI sobre Portugal (quarto ciclo de controlo). Strasbourg: [s.n.]. Disponível em: http://www.coe.int/t/dghl/monitoring/ecri/Country-bycountry/Portugal/PRT-CbC-IV-2013-020-PRT.pdf. Acesso em: 10 abr. 2018.

AHMED, W.; BATH, P. A.; SBAFFI, L.; DEMARTINI, G. Moral panic through the lens of Twitter: an analysis of infectious disease outbreaks. In: PROCEEDINGS OF THE 9TH INTERNATIONAL CONFERENCE ON SOCIAL MEDIA AND SOCIETY. Copenhagen, Denmark, jul. 2018. Anais... Disponível em: http://nrl. northumbria.ac.uk/35066/. Acesso em: 2 maio 2019.

ALEXANDRE, V. O império e a ideia de raça. In: VALA, J. (Ed.). Novos racismos: perspectivas comparadas. Oeiras: Celta Editora, 1999. p. 140-167.

ALEXANDRE, V. O Império Africano (Séculos XIX-XX): as linhas gerais. In: ALEXANDRE, V. (Ed.). O Império Africano (Séculos XIX-XX). Lisboa: Edições Colibri, 2000. p. 11-28.

ALTHUSSER, L. Aparelhos ideológicos de Estado: nota sobre os aparelhos ideológicos de Estado. Rio de Janeiro: Edições Graal, 1983.

ANDERSON, M.; HITLIN, P. Social Media Conversations About Race. Pew Research Center, n. ago, 2016. Disponível em: https://www.pewinternet.org/2016/08/15/social-media-conversations-about-race/. Acesso em: 12 abr. 2018.

APPADURAI, A. O medo ao pequeno número: ensaio sobre a geografia da raiva. São Paulo: Iluminuras, 2009. ARAÚJO, M.; MAESO, S. R. A presença ausente do racial: discursos políticos e pedagógicos sobre História, «Portugal» e (pós-)colonialismo. Educar em Revista, Curitiba, n. 47, p. 145-171, 2013.

AWAN, I. Islamophobia and twitter: A typology of online hate against muslims on social media. Policy and Internet, v. 6, n. 2, 2014. Disponível em: https://www.researchgate.net. Acesso em: 2 maio 2018. 
BATRINCA, B.; TRELEAVEN, P. C. Social media analytics: a survey of techniques, tools and platforms. AI and Society, v. 30, n. 1, p. 89-116, 2014. Disponível em: https://link.springer.com/article/10.1007/s00146014-0549-4. Acesso em: 21 jun. 2017.

BEN-DAVID, A.; MATAMOROS-FERNÁNDEZ, A. Hate speech and covert discrimination on social media: Monitoring the Facebook pages of extreme-right political parties in Spain. International Journal of Communication, v. 10, n. 2016, p. 1167-1193, 2016. Disponível em: https://ijoc.org/index.php/ijoc/article/ view/3697. Acesso em: 22 abr. 2018.

BONILLA-SILVA, E. Racism without racists: Color-Blind racism and the persistence of racial inequality in the United States. 2nd ed. Lanham: Rowman \& Littlefield Publishers, Inc, 2006.

BONILLA-SILVA, E.; LEWIS, A.; EMBRICK, D. G. "I did not get that job because of a black man...”: The story lines and testimonies of color-blind racism. Sociological Forum, v. 19, n. 4, p. 555-581, 2004. Disponível em: https://www.jstor.org/stable/4148829. Acesso em: 28 jun. 2017.

BOURDIEU, P. O poder simbólico. Rio de Janeiro: Bertrand Brasil, 2000.

BRAUN, V.; CLARKE, V. Using thematic analysis in psychology. Qualitative Research in Psychology, v. 3, n. 2, p. 77-101, 2006. Disponível em: https://www.researchgate.net/publication/235356393_Using_ Thematic_Analysis_in_Psychology. Acesso em: 25 nov. 2018.

CABECINHAS, R.; AMÂNCIO, L. Dominação e exclusão: representações sociais sobre minorias raciais e étnicas. Braga: Universidade do Minho, 2004.

CABECINHAS, R.; CUNHA, L. Colonialismo, identidade nacional e representações do "negro". Estudos do século XX, v. 3, p. 157-184, 2003. Disponível em: http://repositorium.sdum.uminho.pt/handle/1822/1791. Acesso em: 10 dez. 2018.

CAPELA, J. Moçambique no século XIX. In: VALENTIM (Ed.). O Império Africano (Séculos XIX-XX). Lisboa: Edições Colibri, 2000. p. 117-134.

CARDOSO, G.; JACOBETTY, P. Surfando a crise: culturas de pertença e mudança social em rede. In: CARDOSO, G. (Ed.). A sociedade dos ecrãs. Lisboa: Tinta da China, 2013.

CASTELLS, M. O poder da identidade. In: O poder da identidade. Lisboa: Fundação Calouste Gulbenkian, 2003.

CASTELO, C. O modo português de estar no mundo: o Luso-Tropicalismo e a ideologia colonial portuguesa (1933-1961). Porto: Edições Afrontamento, 2011.

DIAS, J. R. Relações portuguesas com as sociedades africanas em Angola no século XIX. In: ALEXANDRE, V. (Ed.). O Império Africano (Séculos XIX-XX). Lisboa: Edições Colibri, 2000. p. 69-93.

DIAS, N. “Construir as cidades para os outros”: imigração e trabalho no Portugal contemporâneo. In: DIAS, N.; DIAS, B. P. (Eds.). Imigração e racismo em Portugal: o lugar do outro. Lisboa: Edições 70, 2012. p. 29-45.

DIJK, T. VAN. Discurso e poder. 2 ed. São Paulo: Contexto, 2012.

FAULKNER, N.; BLIUC, A. M. 'It's okay to be racist': moral disengagement in online discussions of racist incidents in Australia. Ethnic and Racial Studies, v. 39, n. 14, p. 2545-2563, 2016. Disponível em: https:// www.tandfonline.com/doi/abs/10.1080/01419870.2016.1171370. Acesso em: 15 maio 2019.

HENRIQUES, J. G. Racismo no país dos brancos costumes. Lisboa: Tinta da China, 2018.

HITLIN, P. Methodology: How Crimson Hexagon Works. 1 abril 2015. Disponível em: http://www. journalism.org/2015/04/01/methodology-crimson-hexagon/. Acesso em: 11 jun. 2018. 
HUGHEY, M. W.; DANIELS, J. Racist comments at online news sites: A methodological dilemma for discourse analysis. Media, Culture and Society, v. 35, n. 3, p. 332-347, 2013. Disponível em: https:// journals.sagepub.com/doi/abs/10.1177/0163443712472089?journalCode=mcsa. Acesso em: 21 dez. 2018.

JOSEPH, S. Social media, political change, and human rights. Boston College International and Comparative Law Review, v. 35, n. 1, p. 145-188, 2012. Disponível em: https://lawdigitalcommons.bc.edu/ cgi/viewcontent.cgi?article=1667\&context=iclr. Acesso em: 25 out. 2018.

MALESIC, M. The securitisation of migrations in Europe: the case of Slovenia. Teorija in Praksa, v. 54, n. 6, p. 947-968, 2017. Disponível em: https://www.researchgate.net. Acesso em: 8 jul. 2018.

MARQUES, J. P. Portugal e o abolicionismo. In: ALEXANDRE, V. (Ed.). O Império Africano (Séculos XIX-XX). Lisboa: Edições Colibri, 2000. p. 31-54.

MBEMBE, A. Necropolítica. Arte \& Ensaios, v. 2, n. 32, p. 123-151, 2016. Disponível em: https://revistas. ufrj.br/index.php/ae/article/view/8993. Acesso em: 20 out. 2019.

MEERTENS, R.; PETTIGREW, T. Será o racismo subtil mesmo racismo? In: VALA, J. (Ed.). Novos racismos: perspectivas comparadas. Oeiras: Celta Editora, 1999.

NETO, M. DA C. Angola no século XX (até 1974). In: VALENTIM (Ed.). O Império Africano (Séculos XIX-XX). Lisboa: Edições Colibri, 2000. p. 175-195.

OLIVEIRA, N. "Portugal não é um país pequeno”. Reloaded - «Terceira Via» ou despolitização da diferença? In: DIAS, B. P.; DIAS, N. (Eds.). Imigração e racismo em Portugal: o lugar do outro. Lisboa: Edições 70, 2012. p. 47-71.

RAPOSO, O.; VARELA, P. Faces do racismo nas periferias de Lisboa: uma reflexão sobre a segregação e a violência policial na Cova da Moura. In: IX Congresso Português de Sociologia. Faro, 6 a 8 jul. 2016. Anais... Disponível em: https://repositorio.iscte-iul.pt/handle/10071/16337. Acesso em: 2 jun. 2018.

RECUERO, R. Social Media and Symbolic Violence. Social Media and Society, v. 1, n. 1, p. 1-3, 2015. Disponível em: https://journals.sagepub.com/doi/10.1177/2056305115580332. Acesso em: 10 ago. 2018.

STEINFELDT, J. A.; FOLTZ, B. D.; KALADOW, J. K.; CARLSON, T. N.; PAGANO, L. A.; BENTON, E.; STEINFELDT, M. C. Racism in the electronic age: Role of online forums in expressing racial attitudes about American Indians. Cultural Diversity and Ethnic Minority Psychology, v. 16, n. 3, p. 1-11, 2010. Disponível em: https://www.ncbi.nlm.nih.gov/pubmed/20658879. Acesso em: 13 jul. 2018.

SUNSTEIN, C. R. \#Republic: divided democracy in the age of social media. Princeton: Princeton University Press, 2017.

TAGUIEFF, P. A. The New Cultural Racism in France. Telos, v. 1990, n. 83, p. 109-122, 1990. Disponivel em: https://philpapers.org/rec/TAGTNC. Acesso em: 21 jan. 2019.

TORRES, A. A economia do Império (Séculos XIX-XX). In: ALEXANDRE, V. (Ed.). O Império Africano (Séculos XIX-XX). Lisboa: Edições Colibri, 2000. p. 55-67.

VALA, J.; ALEXANDRE, V. Novos racismos: perspectivas comparativas. Lisboa: Celta Editora, 1999.

VALA, J.; LOPES, D.; BRITO, R. A construção social da diferença: racialização e etnização das minorias. In: VALA, J. (Ed.). Novos racismos: perspectivas comparadas. Oeiras: Celta Editora, 1999. p. 145-168.

YAQUB, U.; CHUN, S. A.; ATLURI, V.; VAIDYA, J. Analysis of political discourse on twitter in the context of the 2016 US presidential elections. Government Information Quarterly, v. 34, n. 4, p. 613626, 2017. Disponível em: https://www.sciencedirect.com/science/article/pii/S0740624X17301910. Acesso em: 18 fev. 2019. 


\section{Beatriz Nascimento Teles}

Mestre em História Social das Relações Políticas pela Universidade Federal do Espírito Santo e Doutoranda em Ciências da Comunicação pelo Instituto Universitário de Lisboa (ISCTE-IUL). Tem experiência em pesquisa sobre Fascismo italiano, propaganda política e o cinema neorrealista da década de 1940 produzido na Itália. Atualmente, tem se dedicado à análise do discurso racista nas redes sociais em Portugal, tema em desenvolvimento na sua tese de Doutorado. E-mail: bntso@iscte-iul.pt.

Recebido em: 24.06.2019

Aprovado em: 16.11.2019 